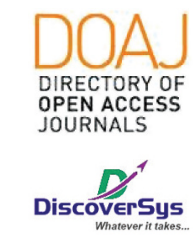

Published by DiscoverSys

\section{Skin flap pattern in skin cancer at Sanglah General Hospital Denpasar, Bali-Indonesia}

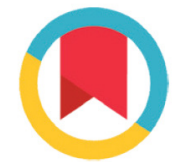

CrossMark

\author{
Made Wardhana ${ }^{1 *}$, IGN Darmaputra', I Gde Nengah Adhilaksman Sunyamurti Wirawan', \\ Nyoman Yoga Maya Pramita ${ }^{1}$, Rikcy Fernando Maharis ${ }^{1}$, Ni Made Dwi Puspawati ${ }^{1}$, \\ IGAA Dwi Karmila' ${ }^{1}$ IGAA Praharsini ${ }^{1}$
}

'Department of Dermatology and Venereology, Faculty of Medicine, Universitas Udayana-Sanglah General Hospital, Bali-Indonesia

*Corresponding to : Made Wardhana, Department of Dermatology and Venereology, Faculty of Medicine, Universitas Udayana-Sanglah General Hospital, Bali-Indonesia; wardhanamade@unud.ac.id

Received: 2019-06-04 Accepted: 2019-09-07 Published: 2019-12-01

\section{INTRODUCTION}

Skin cancer can be classified into three main histological subtypes consisting of melanoma, basalioma, and squamous cell cancer (SCC) as well as several other uncommon subtypes such as keratoacanthoma, Bechet disease, and pyogenic granuloma. More than 3.5 million cases of skin cancer are discovered in the United States that makes it the most common cancer in the United States. The diagnosis of skin cancer is made by elaborating all the findings from the clinical history, clinical examination, characteristics of skin lesion, and supporting examination such as dermoscopy and histopathological study; the latter is considered the gold standard diagnostic modality for skin cancer. Management of skin cancer includes various kinds of intervention, namely retrospectively using patients' medical records from January 2015 - December 2018.

Results: Over the study period, there were a total of 41 skin cancer patients who underwent skin flap surgery of whom 10 (54.6\%) patients were diagnosed with melanoma, 16 patients with basalioma, 9 patients with $\mathrm{SCC}$ and the remaining included 3 cases of acanthoma and 1 Bechet disease. Regarding the flap types, simple advancement and its variances were performed in 6 melanoma, 11 basaliomas, $5 \mathrm{SCC}$ and 4 keratoacanthoma cases. Transposition flap was performed in 2 melanoma, 3 basalioma, and $3 \mathrm{SCC}$ cases; whereas rotation flap was performed in 2 melanoma and 2 basaliomas and $S C C$ cases.

Conclusion: From 41 skin cancer patients discovered, basalioma was the most frequent cases and advancement techniques were the most frequently performed flap surgery. Only 1 post-surgical infection was found after rotational flap procedure.

Keywords: Skin cancer profile, skin flap, complication

Cite This Article: Wardhana, M., Darmaputra, I.G.N., Wirawan, I.G.N.A.S., Pramita, N.Y.M., Maharis, R.F., Puspawati, N.M.D., Karmila, I.G.A.A.D., Praharsini, I.G.A.A. 2019. Skin flap pattern in skin cancer at Sanglah General Hospital Denpasar, Bali-Indonesia. Intisari Sains Medis 10 (3): 600-603. D0l: 10.15562/ism.v10i3.518

immunotherapy, cryosurgery, and conventional surgery (scalpel survey). There are four different approaches in post-operative wound management performed at surgery division, including left-open approach where the surgical wound is left open intentionally and the healing process is achieved through secondary mechanism; wound closure by suturing the wound that promotes primary healing process; and wound closure through application of additional procedure either using skin flap or graft. Skin flap is performed when the primary closure is not feasible to close the skin defect resulted from tumour excision, particularly when the defect is too large, too stretched, or primary closure would result in an aesthetically unpleasant result. ${ }^{1,2}$ Random pattern flap is a procedure performed by detaching a skin with a certain thickness from the donor site 
to the defect while maintaining its blood supply through vascular pedicle. ${ }^{3}$ In terms of its movement, random pattern flap is divided into four different types, including advancement flap, transposition flap, rotation flap, and interpolation flap. ${ }^{4}$

Surgical defect after extirpation procedure is a challenge in the field of dermatologic surgery since the chosen technique for wound closure

Table 1. Characteristics of Skin Cancer Cases

\begin{tabular}{|c|c|c|c|c|}
\hline & $\begin{array}{c}\text { Melanoma } \\
(n, \%) \\
10(24.4)\end{array}$ & $\begin{array}{c}\text { Basalioma } \\
\text { (n, \%) } \\
18(43.9)\end{array}$ & $\begin{array}{c}\text { SCC } \\
(n, \%) \\
9(21.9)\end{array}$ & $\begin{array}{c}\text { Others }(\mathrm{n}, \%)^{*} \\
4(9.8)\end{array}$ \\
\hline \multicolumn{5}{|l|}{ Sex } \\
\hline Male & $6(14.6)$ & $11(26.8)$ & $3(7.3)$ & $3(7.3)$ \\
\hline Female & $4(9.8)$ & $7(17.1)$ & $6(14.6)$ & $1(2.4)$ \\
\hline \multicolumn{5}{|l|}{ Age } \\
\hline$<50$ years & $4(9.8)$ & $5(12.2)$ & $2(4.8)$ & - \\
\hline$>50$ years & $6(14.6)$ & $13(31.7)$ & $7(17.1)$ & $4(9.8)$ \\
\hline \multicolumn{5}{|l|}{ Skin type } \\
\hline I-II & $4(9.8)$ & $3(7.3)$ & $5(12.2)$ & - \\
\hline II-IV & $6(14.6)$ & $13(31.7)$ & $3(7.3)$ & $4(9.8)$ \\
\hline V-VI & - & $2(4.8)$ & 1 & - \\
\hline \multicolumn{5}{|l|}{ Occupation } \\
\hline Outdoor & $8(19.5)$ & $12(29.3)$ & $7(17.1)$ & $3(7.3)$ \\
\hline Indoor & $2(4.8)$ & $6(14.6)$ & $2(4.8)$ & $1(2.4)$ \\
\hline \multicolumn{5}{|l|}{ Location } \\
\hline Face & $8(19.5)$ & $15(36.6)$ & $6(14.6)$ & $3(7.3)$ \\
\hline Trunk/back & $2(4.8)$ & $3(7.3)$ & $3(7.3)$ & $1(2.4)$ \\
\hline \multicolumn{5}{|l|}{ Skin flap technique } \\
\hline Simple Advancement & $6(14.6)$ & $12(29.3)$ & $5(12.2)$ & $4(9.8)$ \\
\hline Tranposition & $2(4.8)$ & $4(9.8)$ & $3(7.3)$ & - \\
\hline Rotation & $2(4.8)$ & $2(4.8)$ & $1(2.4)$ & - \\
\hline
\end{tabular}

*) Keratoacanthoma (3), Bechet (1)

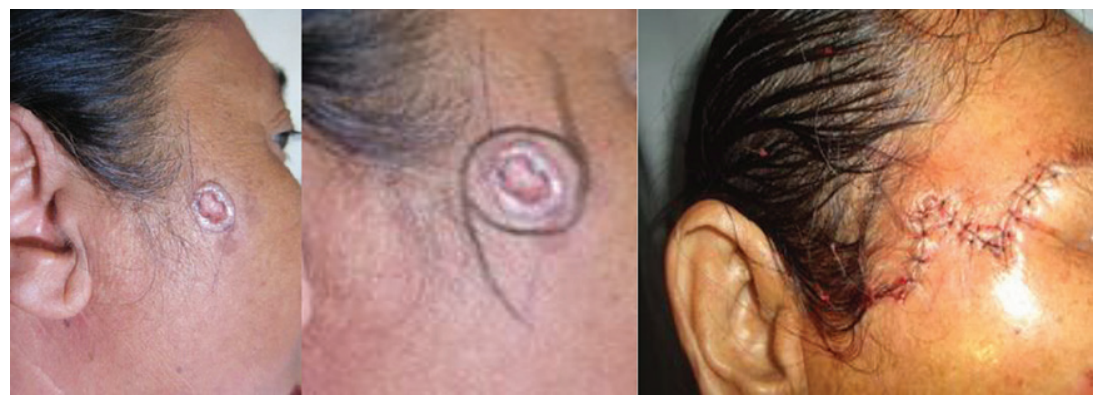

Figure 1. Example of $\mathrm{O}$ to $\mathrm{Z}$ flap

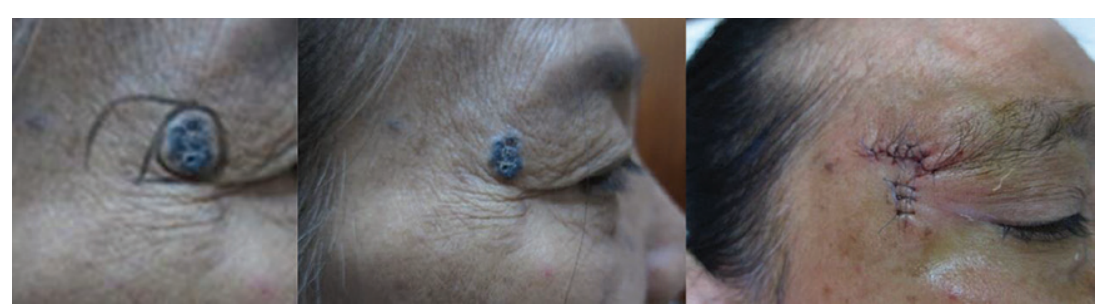

Figure 2. Example of rotation flap would determine the final results cosmetically, particularly to prevent any distortions. There are several available methods for post-operative wound closure, including secondary wound healing, primary closure, skin graft and skin flap. ${ }^{3}$

Random pattern flap is wound closure technique performed by detaching an area of the skin with a pre-determined thickness from the donor site to the post-operative defect while maintaining its blood supply through vascular pedicle. In this regard, there are two sequential skin transplantation processes which consist of primary transplantation of the flap to the skin defect and secondary displacement of the tissue covering the secondary defect that also facilitate the displacement of the primary flap.,

In the following section, we present several techniques of skin flap surgery that have ever been conducted at dermatologic surgery division of Dermatology and Venereology Clinic, Sanglah General Hospital Denpasar. These documentations of our patients are presented in a sequential order of pre-, during, and post-surgery. Objective: To investigate the pattern of skin flap transplantation performed in the management of skin cancer at Dermatology and Venereology Clinic, Sanglah General Hospital, from January 2015 - December 2018.

\section{SUBJECTS AND METHODS}

This descriptive study was conducted retrospectively in skin cancer patients who underwent skin flap surgery in January 2015 until December 2018. The data were collected from the patient's medical record and the results are presented in several groups based on the histological subtype of the skin cancer, age, sex, skin type, and the flap technique performed.

\section{RESULTS}

Among all of the new patients visiting Dermatology and Venereology Clinic, Sanglah General Hospital, Denpasar, a total of 41 skin cancer patients were documented to have undergone surgical excision procedure. The types of post-surgical wound closure technique performed consisted of primary wound healing after skin flap placement. The overall results are presented in Table 1. All case and example of various flap in our center can be seen in figure 1 until 6.

\section{DISCUSSION}

Selection of appropriate post-operative wound closure is an important determinant of the final cosmetic results, particularly to prevent any 


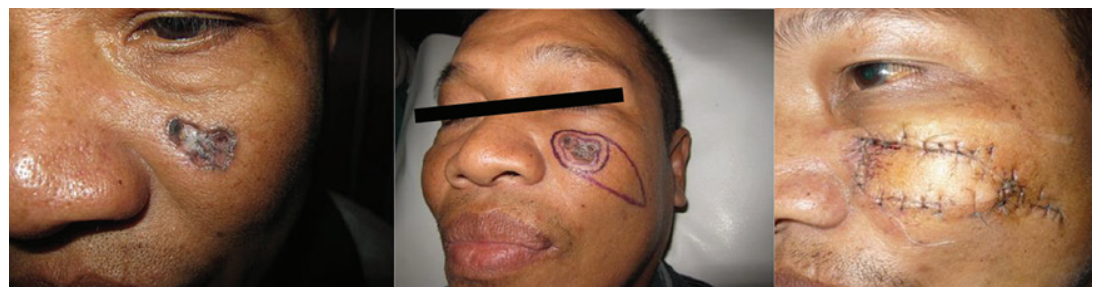

Figure 3. Example of island pedicle flap



Figure 4. Example of $\mathrm{V}$ to $\mathrm{T}$ flap

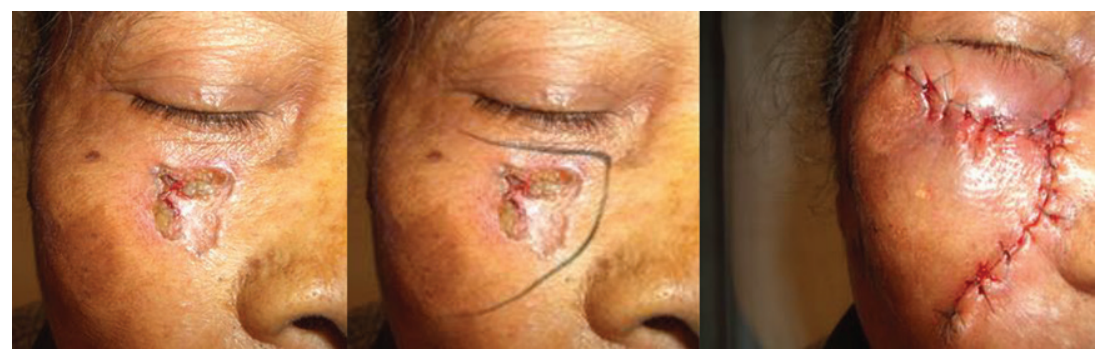

Figure 5. Single pedicle advancement flap

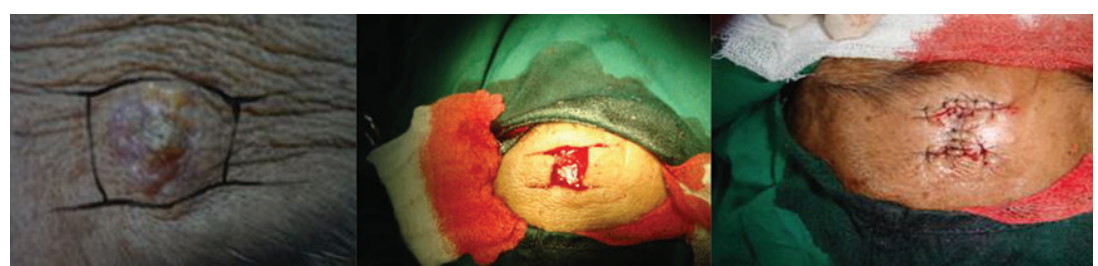

Figure 6. H plasty advancement

distortions. There are several techniques available for closing post-operative wound, including secondary wound healing, primary closure, skin graft and skin flap., ${ }^{3,4}$ Skin flap is commonly used when the simple primary closure is not feasible when the defect is too large, too many stretches, or when the procedure would result in either functional or cosmetic compromise. Skin flap is performed by detaching an area of the skin with a pre-determined thickness from the donor site to the post-operative defect while maintaining its blood supply through vascular pedicle. ${ }^{5-7}$

In general, several flap types are frequently performed in dermatologic surgery by using local anesthesia only if the lesion is on close-knit with other body organs such as eye. Regarding its vascularization, skin flaps are classified into: Axial flap, supplied by identifiable blood vessels (it has a name); Random flap, supplied by unidentifiable blood vessels and dermal or subdermal plexus; in most cases, the flaps used are the random flaps. ${ }^{8.9}$

In terms of the methods of donor tissue replacement, skin flaps are categorized into: Distant flap where the skin flap is harvested from a distant donor site relative to the primary defect; this kind of flap usually requires re-anastomoses from the donor vasculature to the recipient vasculature at the defect area and it is most commonly used by a surgeon..$^{1,10}$ Local flaps where the skin flap is obtained from the adjacent tissue or surrounding the primary defect; the skin flap movements can be advancement, rotation, transposition or interpolation. Several examples of this flap type include V-Y, rhomboid flap, Z-plasty, O to Z, V to T, and many more. ${ }^{10,11}$

The results of this retrospective study using the data from January 2019 - December 2018 at dermatologic surgery division of Dermatology and Venereology Clinic, Sanglah General Hospital, Denpasar showed that a total of 41 skin cancer cases undergoing skin flap transplantation. From the data, we discovered 10 cases of malignant melanoma, 16 cases of basalioma, and squamous cell carcinoma and keratoacanthoma. As a common theory, malignant skin tumor usually occurs beyond the age of 50 years. In the previous section, we presented the examples of several flap techniques that have been performed in our dermatologic surgery division. These documentations of our patients are presented in a sequential order of pre-, during, and post-surgery.

\section{CONCLUSION}

In our retrospective analysis, we found a total of 41 patients with skin cancer who underwent random pattern flaps. The cohort consisted of 10 (54.6\%) cases of melanoma, 16 cases of basalioma, 9 cases of SCC and other uncommon types, including 3 cases of keratoacanthoma and 1 case of Bechet disease. Regarding the flap types, simple advancement and its variances were performed in 6 melanoma, 11 basaliomas, 5 SCC and 4 keratoacanthoma cases. Transposition flap was performed in 2 melanoma, 3 basalioma, and 3 SCC cases; whereas rotation flap was performed in 2 melanoma and 2 basaliomas and SCC cases.

\section{CONFLICT OF INTEREST}

Auhtor declares there is no conflict of interest regarding publication of this article

\section{ETHICS IN PUBLICATION}

All sample had received signed informed consent 
for publication of their respective photograph in journal article. Current study has been approved by Local Ethical Committee Faculty of Medicine Universitas Udayana/Sanglah General Hospital.

\section{FUNDING}

Current study doesn't receive any specific grant from government or any private sectors.

\section{REFERENCES}

1. Apalla Z, Lallas A, Sotiriou E, Lazaridou E, and Ioannides D. Epidemiological trends in skin cancer. Dermatol Pract Concept. 2017;7(2):1-7

2. Tschoi M, Erik A, Hoy BS, Mark S. Skin Flaps. Surg Clin N Am. 2009;89:643-658

3. Spencer JM. Rotation Flaps [Internet]. England: Web MD; 2007 February 28 [cited 2010 Feb 28]. Available at : http:// www.emedicine.com.

4. Krishna GP, Jonathan MS. Concepts in local flap design and classification. Operative Techniques in Otolaryngology. 2011;22:13-23.

5. Bennet R. Surgical Complication. In: Wolff K, Goldsmith LA, Katz SI, Gilchrest BA, Paller AS, Leffell DJ, editors. Fitzpatrick's Dermatology In General Medicine, $7^{\text {th }}$ ed. USA: McGraw-Hill Company, 2008, p: 2336 - 2341.
6. Robinson JK. Excisional Surgery and Repair, Including Flaps and Grafts. In: Wolff K, Goldsmith LA, Katz SI, Gilchrest BA, Paller AS, Leffell DJ, editors. Fitzpatrick's Dermatology In General Medicine, $7^{\text {th }}$ ed. USA: McGrawHill Company. 2008, p:2302-2312.

7. Khouri R. Skin Flap. In: Nouri K, Leal-Khouri S. Techniques in Dermatologic Surgery. Spain: Mosby, 2003, p:141-151.

8. Cook Jl, Goldman GD. Random Pattern Cutaneous Flaps. In: Robinson JK, Hanke CW, Sengelmann RD, Siegel DM, editors. Surgery of The Skin. Spain: Mosby Elsevier, 2005, p: 311-344.

9. Waleed EMT, Hafez, Reda A. Younis, Loai E, Mohamed A, Hegazy S. V-Y Advancement Flap for Reconstruction of Defects after Excision of Basal Cell Carcinoma of the Face. International Journal of Surgical Research. 2014;3(1):1518.

10. Sara AL, Francisco MM, Manuel PC, Francisco M, Camacho M. O to Z flaps in facial reconstructions. An Bras Dermatol. 2015;90(2):258-60.

11. Santos V, Silva R, Passini V, Duarte M, Flores L. Brain Metastasis as Initial Manifestation of Melanoma (A Case Report). Bali Medical Journal. 2016;5(2):295-297. DOI:10.15562/bmj.v5i2.149

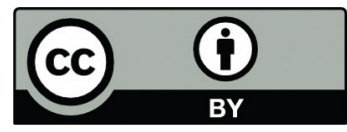

This work is licensed under a Creative Commons Attribution 